\title{
HIERRO Y LAPORTA SOBRE LOS DERECHOS
}

\author{
Manuel Atienza \\ Universidad de Alicante
}

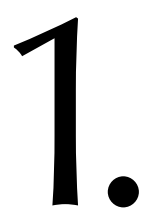

Francisco LAPORTA y Liborio HIERRO han sido para mí, desde que los conocí a mediados de los setenta, dos hermanos mayores en el oficio iusfilosófico. Uso la expresión «hermanos mayores» aproximadamente en el mismo sentido en el que recientemente lo ha hecho uno de ellos - LAPORTApara referirse a sus tres hermanos mayores (Elías DíAZ, Javier MugUERZA y Salvador GINER), aunque variando un poco la connotación del concepto: pues HIERRO y LAPORTA han influido mucho sobre mi manera de ver la filosofía del Derecho, he aprendido también mucho de los dos, pero la verdad es que no recuerdo (quizás por la distancia geográfica en la que hemos vivido) que nunca me hayan impacientado o irritado $^{1}$. Pues bien, una de esas cosas importantes que he aprendido de ellos, y que creo haber transmitido a otros, es a entender adecuadamente lo que significa tener un derecho humano. En efecto, ellos dos, cada uno por separado, escribieron en la década de los ochenta sendos artículos destinados a esclarecer la noción de derechos humanos que, en mi opinión (y en la de muchos otros), constituyen una aportación fundamental en la elaboración de ese concepto, verdaderamente central para la concepción contemporánea del Derecho. Me refiero al artículo de HIERRO publicado en 1982, «¿Derechos humanos o necesidades humanas? Problemas de un concepto» ${ }^{2}$, y al de LAPORTA, en 1987, «El concepto de derechos humanos» ${ }^{3}$. A pesar de ser, como digo, dos trabajos ampliamente conocidos e influyentes entre los iusfilósofos españoles, empezaré por hacer una breve presentación de cada uno de ellos, para luego añadir dos comentarios o, quizás mejor, dos preguntas.

2. HiERRO parte de lo insatisfactorio que resultaba (escribe a comienzos de los ochenta) que el lenguaje de los derechos, ampliamente usado en el debate político, no tuviera una adecuada réplica en el plano teórico. Esa insatisfacción teórica se debería, básicamente, a estos dos factores: a la tendencia a considerar los derechos como algo derivado de los deberes (de manera que el concepto que habría que tomarse en serio sería este último, el de deber); y a que la noción de «derecho subjetivo» a la que había acudido como instrumento teórico el pensamiento jurídico no sólo resulta inadecuada

1 LAPORTA ( «Javier Muguerza y los peldaños hacia los derechos humanos», en VVAA, Diálogos con Javier Muguerza, Madrid, Consejo Superior de Investigaciones Científicas, 2016) afirma que los hermanos mayores (refiriéndose, sin duda, a los tres mencionados, pero no queda claro si a toda la clase de los «hermanos mayores») «tienen como tales, además de la característica de influirnos y enseñarnos mucho, también la de impacientarnos algunas veces y hasta la de irritarnos de vez en cuando» (p. 323).

2 Se publicó en la revista Sistema, núm. 46, enero de 1982.

3 En Doxa, núm. 4. 
para dar cuenta de ciertos derechos humanos, sino que «se ha convertido — decíaen un obstáculo teórico contra cualquier intento de formular una teoría nueva de los derechos» (p. 46).

En relación con esto último, HIERRO se ocupa entonces (y ha seguido haciéndolo después) de analizar las dos teorías clásicas sobre los derechos, la de la voluntad o de la elección y la del interés o del beneficiario. Señala cuáles son las ventajas e inconvenientes de cada una de ellas, en sus diversas variantes. Y opta por una versión de la segunda de esas dos teorías (la teoría del beneficiario de MACCORMICK) que pone en primer plano la noción de necesidad (de ahí el título de su artículo). Lo que a mí me parece más importante del análisis de HIERRO es el haber señalado que el concepto de derechos humanos tiene una dimensión moral inesquivable. Lo que permite distinguir, según él, un simple deber de hacer algo a favor de alguien, de un deber basado en un derecho es precisamente una «diferencia moral»: «Cuando afirmamos que algo debe hacerse a favor de alguien porque tiene derecho a ello, queremos probablemente decir que es bueno hacerle tal cosa y que sería malo dejar de hacerlo. O sea, que se trata de una necesidad, interés o deseo de un sujeto ante la cual se obra bien si y sólo si se la satisface» (p. 54). El que la mayor parte de los derechos tengan la estructura de una libertad significa para él que la «libertad es una, y probablemente la principal, necesidad que entendemos debe ser satisfecha» (p. 57). Y de todo ello concluía esta definición de lo que supone tener un derecho: «Es tener una necesidad cuya satisfacción hay razones suficientes para exigir en todo caso; consecuentemente, tener un derecho es, jurídicamente hablando, tener una necesidad que las normas del sistema jurídico exigen satisfacer en todo caso» (p. 57).

Esa concepción de los derechos tendiente a considerarlos como razones, como necesidades o como valores le lleva a defender la tesis de la correlatividad entre los derechos y los deberes, pero otorgando prioridad a los primeros, a los derechos:

La conclusión es, por tanto, que los derechos implican siempre deberes correlativos y que cuando no haya razones suficientes para imponer sobre nadie tales deberes, es que no hay razones suficientes para afirmar el derecho que, con ellos, se habría de satisfacer. Pero, al mismo tiempo, el punto de vista aquí sostenido supone que los derechos son lógica y axiológicamente anteriores a los deberes. Establecida una necesidad que consideramos exige ser satisfecha en todo caso, por su importancia y por la existencia de posibilidades para hacerlo, podemos luego establecer sobre quién recae el deber correlativo. La existencia del derecho puede, además, sostenerse una vez desaparecido el obligado, estableciéndose entonces el deber sobre otro. En términos de razonamiento moral esto significa que los derechos sirven como justificación de los deberes (p. 60).

Pues bien, lo que llevó a LAPORTA a escribir el artículo antes recordado fue también su insatisfacción ante la falta de precisión teórica con que se manejaba el concepto de derechos humanos. En particular, a él le parecía intuitivamente incompatible la tendencia a aumentar la nómina de los derechos humanos con la idea de que estos constituyen las exigencias de carácter más básico — más fuertes- de los sistemas morales, políticos y jurídicos. Y la ratificación de esa intuición, su conversión en una tesis teóricamente fundada, tiene lugar, en el artículo de LAPORTA, a través de una concepción de los derechos humanos que se puede articular en dos pasos.

En el primero, se trata de aclarar qué significa una expresión del tipo «A tiene derecho a X». La respuesta de LAPORTA es que esa noción, la de tener derecho, es relativa a un sistema normativo, pero no exclusivamente de carácter jurídico, de ma- 
nera que los derechos pueden ser también derechos morales. Pero además, y esto es lo fundamental, los derechos no hacen referencia, en su opinión, tanto a las normas como a las razones que justifican la existencia de esas normas; o sea, que una cosa son los derechos, y otra las técnicas de protección de los derechos: «Los derechos son, por así decirlo, la expresión de una especial consideración que los sistemas normativos atribuyen a ciertas situaciones o estados de cosas relativos a los individuos de una cierta clase. En realidad estas parecen ser siempre las dos dimensiones básicas de la noción de "derecho": El valor especial que atribuye a un cierto estado de cosas como digno de protección y la adscripción "individualizada" (en sentido amplio) de ese bien o beneficio y su protección» (p. 29). Y LAPORTA presenta una definición de la noción de derecho también inspirada (como la de HIERRO) en MACCORMICK y cuyos componentes serían: $[\ldots]$.

a) La adscripción a todos y cada uno de los miembros individuales de una clase de

b) [...] una posición, situación, aspecto, estados de cosas, etc.

c) [...] que se considera por el sistema normativo un bien tal que constituye una razón fuerte $[\ldots]$.

d) [...] para articular una protección normativa en su favor a través de la imposición de deberes u obligaciones, la atribución de poderes e inmunidades, la puesta a disposición de técnicas reclamatorias, etc. (p. 31).

El segundo paso que LAPORTA da en su artículo consiste en señalar cuáles son los rasgos formales y estructurales de la noción de derechos humanos. De acuerdo con él, se trataría de la universalidad (se adscriben a todos los seres humanos), el carácter absoluto (las razones que proveen son las que tienen un carácter más fuerte) y la inalienabilidad (son atribuidos a cada uno ineludiblemente, al margen de su consentimiento o contra él). Lo que significa que «los derechos humanos tratan de configurarse como una forma de expresión de los propios rasgos constitutivos de la moralidad interindividual, o, para utilizar un lenguaje kantianizado, de las condiciones de posibilidad del mundo moral» (p. 44).

3. El primero de mis comentarios proviene de una comparación entre esos dos trabajos y, más en general, entre la concepción de cada uno de nuestros autores sobre los derechos humanos. Y lo que hay que decir al respecto es que se trata de dos visiones de los derechos no únicamente compatibles entre sí, sino coincidentes en lo esencial. En realidad, las contribuciones de HIERRO y de LAPORTA son la expresión, en el campo de la iusfilosofía española, del cambio que por aquella época (a partir de finales de los setenta) estaba teniendo lugar en la iusfilosofía analítica anglosajona: el paso de una concepción puramente normativista de los derechos (a la manera de HOHFELD o de HART) a otra que los concebía más bien en términos de valores, de bienes o de razones (como es el caso de MACCORMICK o de Raz). Además, LAPORTA y HIERRO tienen concepciones muy parecidas en materia de ética y de metaética. Ambos son no-cognoscitivistas, pero sólo en la medida en que no creen que exista algo así como hechos morales y, por ello, los juicios morales —en opinión de ambos- no pueden ser calificados como verdaderos o falsos ${ }^{4}$. Ahora bien, los dos están muy lejos

4 Vid., al respecto, el reciente libro de HierRo, Los derechos humanos. Una concepción de la justicia, Madrid, Marcial Pons, 2016; o la entrevista a Francisco LAPORTA publicada también recientemente en Doxa (núm. 38, 2015). 
del emotivismo ético: LAPORTA, por ejemplo, considera que la reflexión de carácter moral ha alcanzado una alta cota «de racionalidad y objetividad» (2015: 563); y HIERRO se ha decantado por un constructivismo ético, en la línea de RAWLS, de ALEXY o de DwORKIN (2016: 132-133).

Esa esencial coincidencia es compatible, sin embargo, con alguna diferencia de énfasis o de matiz. Así, mientras que el planteamiento de HIERRO, a la hora de configurar el concepto de derechos humanos, parece estar volcado sobre todo hacia los problemas de positivización, el de LAPORTA apunta más bien hacia la fundamentación moral de los derechos. Puede parecer sólo una cuestión de acento, pues ni HIERRO desconoce la importancia de la fundamentación [y de ahí su alejamiento en este punto de BobBIO (vid. Hierro, 2016: 131-132)], ni para LAPORTA es indiferente la cuestión de la positivización (recuérdese cuál había sido la motivación de su artículo). Pero sí podría marcar alguna diferencia el hecho de que lo que estaba detrás del artículo de HIERRO era la necesidad de incorporar derechos humanos (los económicos y sociales o los de los niños) que caían fuera de la concepción tradicional, mientras que el objetivo de LAPORTA iba en el sentido opuesto, o sea, lo que él buscaba era mostrar la necesidad de no ampliar, o de restringir, el elenco de los derechos. Insisto en que se trata únicamente de una cuestión de acentos, pero me pregunto (y pregunto a los autores) si esa posible diferencia ${ }^{5}$ tiene que ver con sus discrepancias en relación con la interpretación de la noción de Estado de Derecho y, en particular, del imperio de la ley: la de HIERRO — según sus propias palabras- sería una interpretación «fuerte», al introducir el elemento democrático, y la de LAPORTA, «débil», pues sólo tomaría en cuenta «criterios estructurales en la formulación y aplicación de las normas jurídicas» ${ }^{6}$.

Y el segundo y último comentario tiene directamente la forma de una pregunta que, en realidad, ya les he hecho, en alguna ocasión, a ambos: ¿Por qué su empeño en seguir considerándose como autores iuspositivistas cuando sus concepciones de los derechos tendrían que llevarles más bien hacia lo que hoy solemos llamar «postpositivismo»? No puedo obviamente entrar en detalles sobre esas dos concepciones del pensamiento jurídico, y me limito a señalar lo siguiente. Si aceptamos la caracterización usual del positivismo jurídico, es obvio que ellos dos suscriben la tesis de las fuentes sociales, pero no es menos obvio que lo mismo hacen los autores postpositivistas e incluso los iusnaturalistas que hoy cuentan [como ha señalado recientemente el propio LAPORTA (2015: 564)]; de manera que ese, simplemente, ha dejado de ser un rasgo a tener en cuenta para caracterizar una concepción del Derecho. Mientras que no es fácil advertir en qué sentido su concepción de los derechos (la de cada uno de ellos) es compatible con alguna interpretación plausible de la tesis de la separación entre el Derecho y la moral, tal y como tradicionalmente la ha entendido el positivismo jurídico. Quizás no sea casual el hecho de que su (de ambos) concepción de los derechos es prácticamente la antítesis de la de KELSEN y claramente distinta de la de HART; y que en sus últimos trabajos, MACCORMICK reconoció que el positivismo jurídico no era una

\footnotetext{
5 HiERro se ha referido a esa tesis de la escasez de los derechos de LAPORTA (en HiERro: 158-159) pero en términos, yo diría, un tanto elusivos.

6 Vid. L. Hierro, «El imperio de la ley y la crisis de la ley», en Doxa, núm. 19, 1996, 4; y F. LAPORTA, «Imperio de la ley. Reflexiones sobre un punto de partida de Elías Díaz», en Doxa, núms. 15-16, vol. II, 1994.
} 
concepción sostenible en ninguna de sus versiones. En resumen, y a riesgo de simplificar mucho una cuestión compleja, lo que yo quiero plantearles es cómo pueden hacer compatibles estas tres tesis que los dos parecen suscribir: la defensa del positivismo jurídico; la asunción de que los derechos humanos juegan un papel central en nuestros ordenamientos jurídicos; y la configuración de estos últimos en términos de valores, bienes o razones morales. 